\title{
Influences of Cooling Regime on the Residual Strength of SCC Incorporating PPF after Fire
}

\author{
Chung-Hao Wu ${ }^{1}$, Yu-Feng Lin ${ }^{1}$, Jen-Hao Chi ${ }^{2}$, Chien-Chih Chen ${ }^{1}$ \\ ${ }^{1}$ Department of Civil Engineering, Chienkuo Technology University \\ No.1, Chiehshou North Road, Chunghau City 500, Taiwan \\ chw@ctu.edu.tw; lyf@ctu.edu.tw; george@ctu.edu.tw \\ ${ }^{2}$ Department of Fire Science, Wufeng University \\ 117, Sec 2, Chiankuo Rd, Minhsiung, Chiayi County 621, Taiwan \\ chi2415@ms19.hinet.net
}

\begin{abstract}
This research aims at the effects of elevated temperatures and cooling regimes on the fire resistance of self-compacting concrete incorporating polypropylene fibre (SCCPPF) and normal self-compacting concrete (SCC). Both concretes were exposed to elevated temperature of $200{ }^{\circ} \mathrm{C}, 400{ }^{\circ} \mathrm{C}, 600{ }^{\circ} \mathrm{C}$ and $800{ }^{\circ} \mathrm{C}$ for a duration of one hour. After fire, the concrete specimens $(\varphi 100 \times 200 \mathrm{~mm})$ were cooled to room temperature using two methods of air cooling and water cooling. The results indicate that the SCC specimens exhibited explosive spelling at elevated temperature, which were dried previously for 3,5 and 7 days before testing. On the contrary, the SCCPPF specimens without dried previously didn't present explosive spelling. The surface cracks of both kinds of concrete specimens become evident by increasing temperature. The surface cracks of specimens with water cooling were wider and concentrated each other compared with those of SCC. The strengths of both specimens decreased with increasing temperature. Different cooling regimes affect the residual compressive strength of concrete. When the temperature reached to $200{ }^{\circ} \mathrm{C}$, the residual compressive strengths of the specimens with air cooling are higher than those of the specimens with water cooling. For the concrete specimens subjected to the temperatures of $200{ }^{\circ} \mathrm{C}$ and $400{ }^{\circ} \mathrm{C}$, two cooling regimes resulted in almost the same residual compressive strength for the SCCPP specimens, but the SCC specimens presented lower residual compressive strengths with water cooling than those with air cooling.
\end{abstract}

Keywords: Elevated Temperatures, Self-Compacting Concrete, Polypropylene Fibre, Residual Strength.

\section{Introduction}

Self-Compacting Concrete (SCC) is a category of high performance concrete that has excellent deformability in the fresh state and high resistance to segregate. It could be placed and compacted under its self weight without applying vibration [1]. The compressive strength of SCC could be higher than ordinary concrete due to its dense microstructure and low permeability. However, these advantages could cause exploding of SCC at high temperature, reducing its strength and stiffness as well as its mass in the form of surface spalling [2]. Some researches indicate that adding polypropylene fibre (PPF) in SCC can be a useful method to prevent explosive spelling at elevated temperature, because the PPFs melt at approximately $160^{\circ} \mathrm{C}$ to $170^{\circ} \mathrm{C}$ to produce the additional porosity and small channels [3-6]. This may lower internal steam pressure in the concrete and reduce the probability of spalling. However, several researches reported that the additional porosity may decrease the residual compressive strength of concrete [7-8]. The experimental conditions, the cure condition of concrete (dry or saturated state) and the heating rate could present the different results. Moreover, the cooling regimes of concrete after exposure to fire also have influence on the residual compressive strength [9]. However, the influence of cooling regimes on the residual strength of SCC containing PPF (SCCPPF) is not fully covered yet, despite the fact that cooling regime is a very important factor especially when fire is extinguished by water in a fire filed. Such that this study aims to investigate the effect of cooling regimes for the SCCPPF after elevated temperature. 


\section{Experimental Program \\ 2.1. Specimen Materials}

The materials for the concrete mixture include water, cement, furnace slag, fly ash, coarse aggregate, fine coarse aggregate and polypropylene fibre. The properties of these materials are as follows:

1. Water: ordinary water, the property meets the requirements of ASTM C 1602

2. Cement: Type I Portland cement with specific gravity of $3.15 \mathrm{~g} / \mathrm{cm}^{3}$, specific surface area of $3400 \mathrm{~cm}^{2} / \mathrm{g}$ and the property meets the requirements of ASTM C 150

3. Blast Furnace Slag: The specific gravity is $2.9 \mathrm{~g} / \mathrm{cm}^{3}$, specific surface area is $6000 \mathrm{~cm}^{2} / \mathrm{g}$, and the property meets the requirements of ASTM C 989

3. Fly Ash: Class F, the specific gravity is $2.63 \mathrm{~g} / \mathrm{cm}^{3}$ and the property meets the requirements of ASTM C 618

4. Fine Aggregate: natural river sand, the specific gravity is $2.62 \mathrm{~g} / \mathrm{cm}^{3}$, water absorption is $1.25 \%$ and

fineness modulus is 2.7

5. Coarse Aggregate: crushed limestone, the specific gravity is $2.63 \mathrm{~g} / \mathrm{cm}^{3}$, water absorption is $1.17 \%, \mathrm{D}_{\max }$ is $19 \mathrm{~mm}$, 6. Polypropylene Fibre: The specific gravity is $0.9 \mathrm{~g} / \mathrm{cm}^{3}$, a length of $20 \mathrm{~mm}$ and the effective diameter is $0.022 \mathrm{~mm}$, the melting temperature is $160^{\circ} \mathrm{C}$, burning temperature is $590^{\circ} \mathrm{C}$ and absorption value is $0 \%$

7. Superplasticizer: The property meets the requirements of CNS 12283 and CNS 12833 Type II

\subsection{Concrete Mixtures}

The mix proportions of concrete are shown in Table 1 . The compressive strength $\left(f^{\prime}{ }_{c}\right)$ is designed as $40 \mathrm{MPa}$, the waterbinder-ratio is 0.35 , the design of slump-flow is $650 \sim 750 \mathrm{~mm}$. Each concrete mixture was cast in cylinder with sizes of $\varphi 100 \times 200 \mathrm{~mm}$ (Figure 1) for the test of compressive strength. Before casting, slump-flow test, U-box test and V-funnel test (Figure 2) were adopted as workability test on fresh concrete of SCCPPF, SCC filling ability and passing ability, respectively according to the ASTM Committee C09.

Table 1: Mix proportions of concrete. $\left(\mathrm{kg} / \mathrm{m}^{3}\right)$.

\begin{tabular}{|c|c|c|c|c|c|c|c|c|c|}
\hline Concrete & \multirow{2}{*}{ W/B } & Cement & Slag & $\begin{array}{c}\text { Fly } \\
\text { Ash }\end{array}$ & Water & $\begin{array}{c}\text { Coarse } \\
\text { Aggregate }\end{array}$ & $\begin{array}{c}\text { Fine } \\
\text { Aggregate }\end{array}$ & SP & PPF \\
\cline { 1 - 10 } SCC & \multirow{2}{*}{0.35} & 356 & 76 & 75 & 178 & 780 & 889 & 8.14 & 0 \\
\cline { 1 - 9 } SCCPPF & 356 & 76 & 76 & 178 & 780 & 889 & 8.14 & 0.9 \\
\hline
\end{tabular}

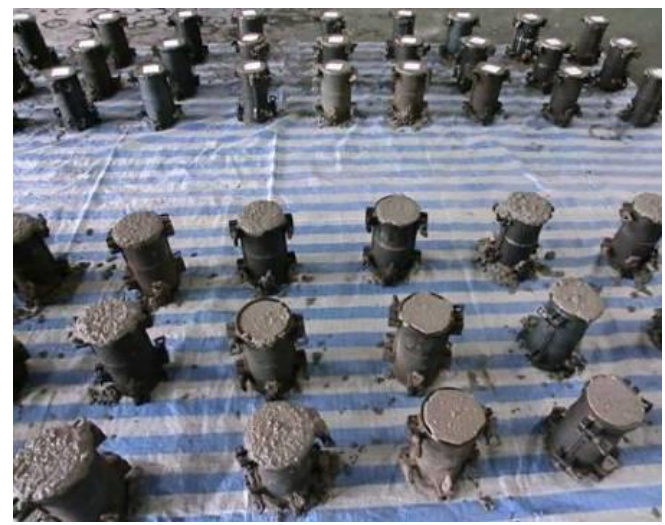

Fig. 1: Concrete specimens. 


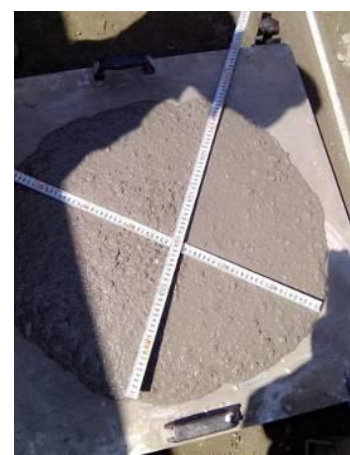

(a) Slump-flow test

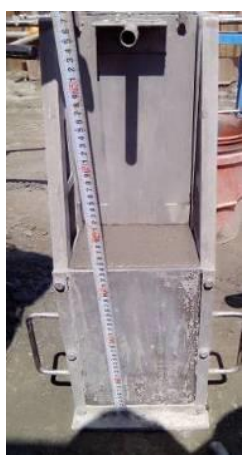

(2) U-box test

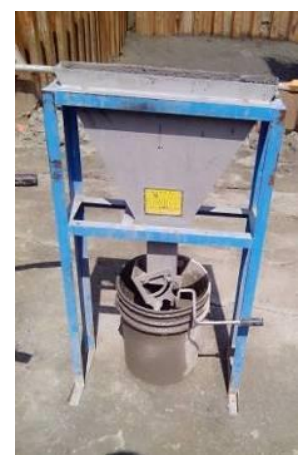

(3) V-funel test

Fig. 2: The workability test of SCC tests.

\subsection{Experimental Procedures}

This research investigates the effect of elevated fire temperature and cooling regimes on the fire resistance of selfcompacting concrete incorporating polypropylene fibre (SCCPPF) and the normal self-compacting concrete (SCC). An electrical box furnace (Figure 3) of chamber size (depth $\times$ width $\times$ height $=700 \mathrm{~mm} \times 400 \mathrm{~mm} \times 400 \mathrm{~mm}$ ) with a maximum temperature of $1200^{\circ} \mathrm{C}$, and heating rate of $5^{\circ} \mathrm{C}$ and $10^{\circ} \mathrm{C}$ per minute was applied for fire tests. The furnace was heated by means of exposed heating elements laid on the refractory walls of the inside chamber. For each test, total of six specimens of size $\varphi 100 \times 200 \mathrm{~mm}$ cylinders were stacked with sufficient space between two adjacent specimens to obtain a uniform heating in each specimen, as shown in Figure 4. One of them was embedded a thermal couple at the centre of specimen to measure the temperature, as shown in Figure 5. Concrete specimens were exposed to the temperature of 200, 400, 600 and $800^{\circ} \mathrm{C}$ for an exposure duration of one hour. After that, the concrete specimens were cooled to room temperature using air cooling and water cooling, as showed in Figure 6. The cooling duration of air cooling was 24 hours, while the water cooling was two hours in water and 22 hours in air. The compressive strength of concrete specimens was tested after cooling, as shown in Figure 7.

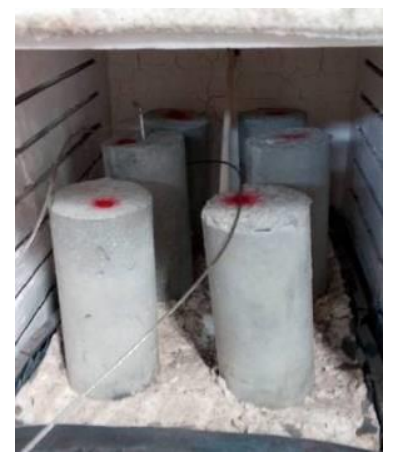

Fig. 3: Electrical box furnace.

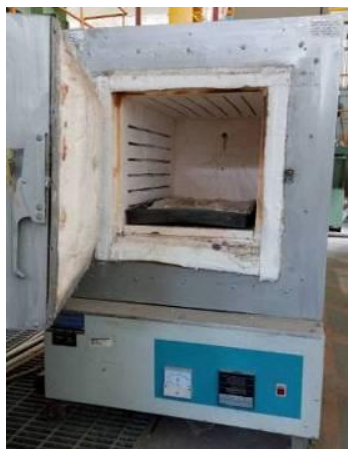

Fig. 4: Specimens in the furnace. 

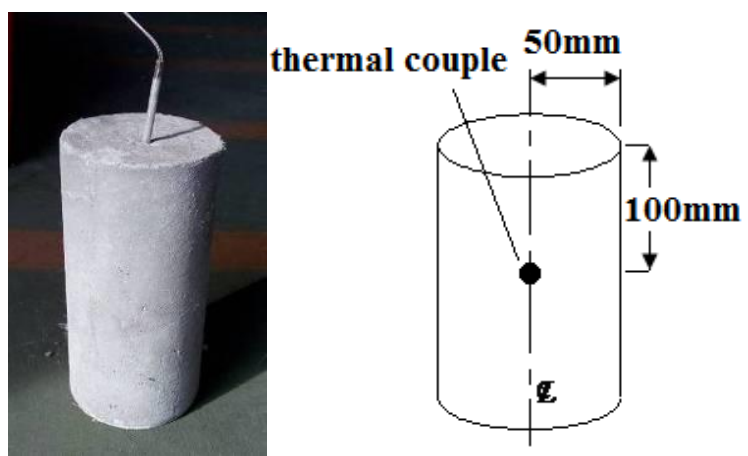

Fig. 5: The thermal couple in the specimen.

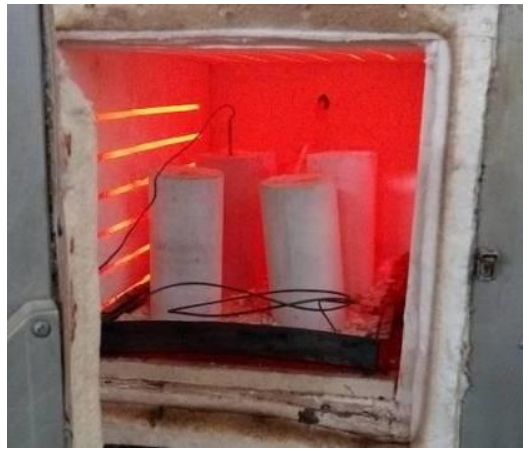

(a) Air cooling

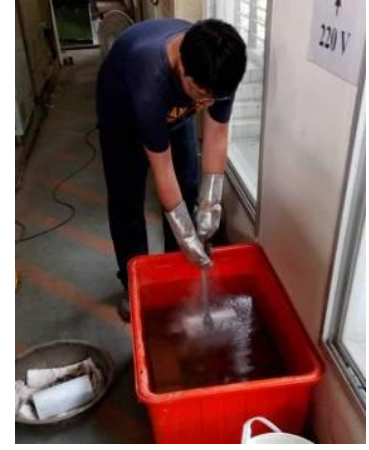

(b) Water cooling

Fig. 6: Cooling regimes.

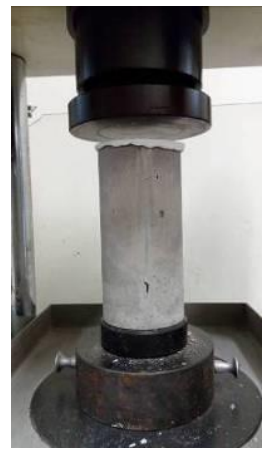

Fig. 7: Compressive strength test.

\section{Results and Discussions}

\subsection{Slump-Flow Test}

The slump-flow values of the self-compacting concrete (SCC) and the self-compacting concrete incorporating polypropylene fibre (SCCPPF) are $745 \mathrm{~mm}$ and $540 \mathrm{~mm}$, respectively. This indicates that adding PPF may decrease the workability of SCC, however, the SCCPPF can still present an adequate workability.

\subsection{Exploding Behaviour of Specimens}

The concrete specimens were placed in the shade of the laboratory without water curing for two and a half years. These specimens were contracted or dried from the cement hydration reaction. Thus, the SCC specimens were heated directly without pre-dried, and the specimens were exploded when the temperature of the electrical box furnace reached about $300{ }^{\circ} \mathrm{C}$ to $400{ }^{\circ} \mathrm{C}$, while the internal temperature of the specimens were between $100{ }^{\circ} \mathrm{C}$ to $200{ }^{\circ} \mathrm{C}$. After fire, the SCC specimens were dried for 3 days, 5 days and 7 days, and the heating rate was reduced from $10{ }^{\circ} \mathrm{C}$ per minute to $5{ }^{\circ} \mathrm{C}$ per minute. It was found that some of them still occurred explosion, as shown in Figure 8. On the other hand, the SCCPPF 
specimens presented no explosion when the temperature of the furnace reaches to $800{ }^{\circ} \mathrm{C}$ with the heated rate of $10{ }^{\circ} \mathrm{C}$ per minute without dried previously.

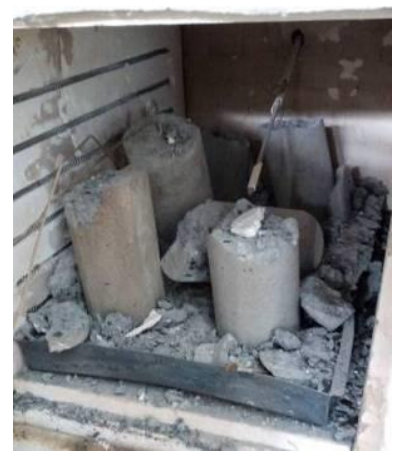

(a) Without dried previously

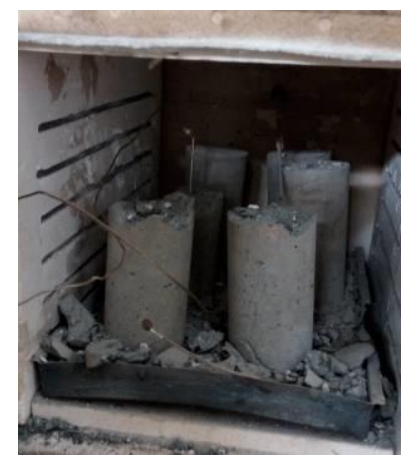

(b) Dried previously for 3 days

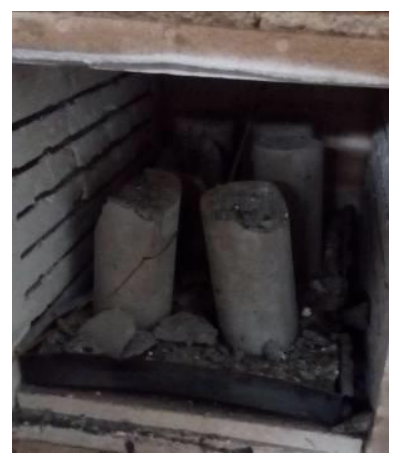

(c) Dried previously for 5 days

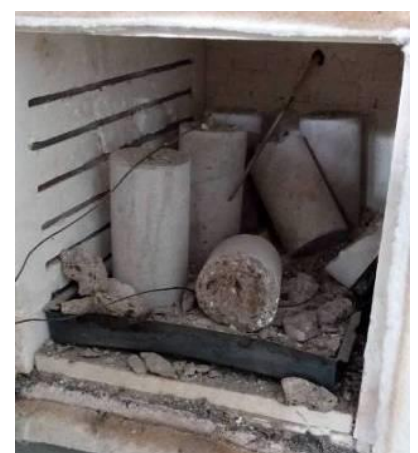

(d) Dried previously for 7 days

Fig. 8: Exploding behaviours of SCC specimens.

\subsection{Surface Cracks of Specimens}

Figure 9 and 10 show the development of surface crack for the SCCPPF specimens after fire. It is seen that, the surface crack of specimens increase with the increase of temperature. When the temperature of the furnace reaches $200{ }^{\circ} \mathrm{C}$, there are no or only few tiny cracks on the surface of specimens either using air cooling or water cooling. The surface cracks increase obviously after the temperature raises to $400{ }^{\circ} \mathrm{C}$. The cracks of the specimen using air cooling are scattered and separated with each other, while the surface cracks of specimen have the potential of connecting each other when using water cooling. The surface cracks of the specimens using both kinds of cooling regimes increase continuously, and the length and width of cracks also increase gradually after the temperature of $600{ }^{\circ} \mathrm{C}$. The surface cracks become serious and interconnected after the temperature of $800{ }^{\circ} \mathrm{C}$, and tend to be obvious especially in the specimens with the water cooling.

The development of the surface cracks of SCC specimens after fire are shown in Figure 11 and 12. The surface cracks of the specimens increases with the increase of the temperature. The surface cracks of specimens using water cooling is more serious than that of specimens using air cooling, but they are not obviouser than those of SCCPPF specimens. This is due to the fact that the PPFs start to melt when the temperature exceeds $160{ }^{\circ} \mathrm{C}$, the melted PPFs may produce the pores in the specimens, that could release the thermal deformation pressure caused by the elevated temperature and thus reduce the probability of explosion On the contrary, the SCC specimens have to resist the thermal deformation pressure, when exceeding the concrete strength the SCC will explode at elevated temperature. Consequently, the strength of SCC specimens was failure to be measured at the temperature of $800{ }^{\circ} \mathrm{C}$, owing to the explosion.

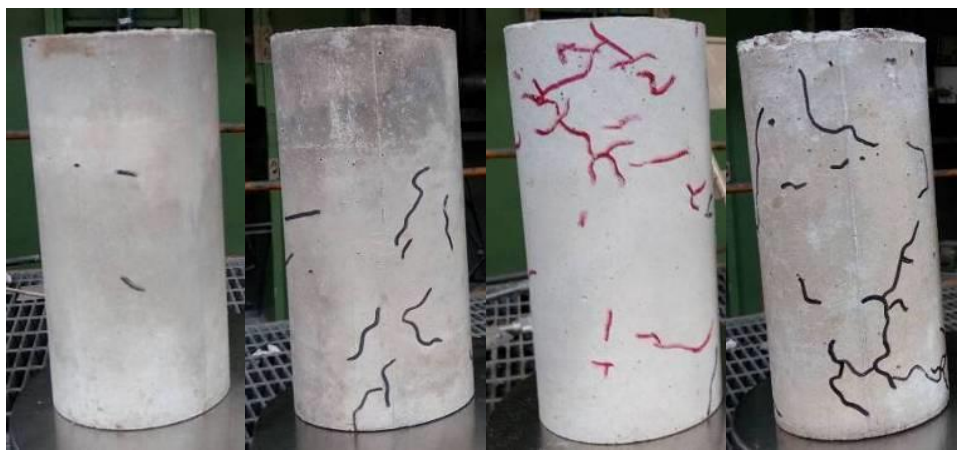
(a) $200{ }^{\circ} \mathrm{C}$
(b) $400{ }^{\circ} \mathrm{C}$
(c) $600{ }^{\circ} \mathrm{C}$
(d) $800{ }^{\circ} \mathrm{C}$

Fig. 9: Surface cracks of SCCPPF specimens using air cooling. 


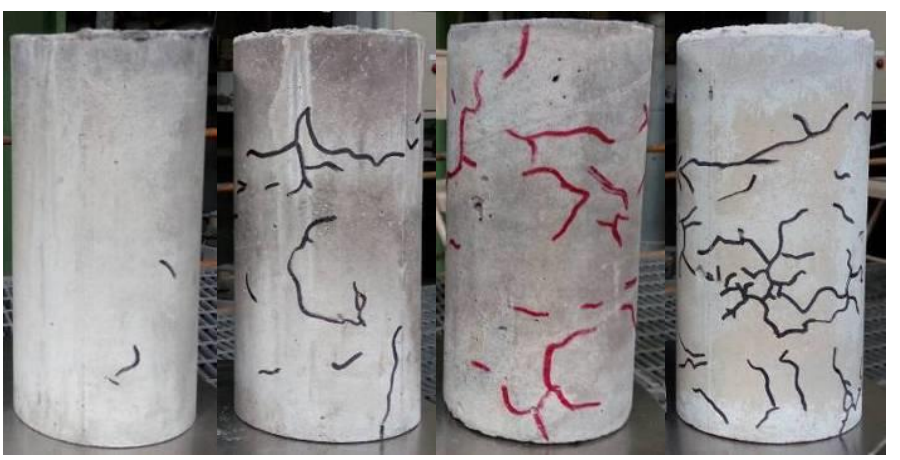
(a) $200{ }^{\circ} \mathrm{C}$
(b) $400{ }^{\circ} \mathrm{C}$
(c) $600{ }^{\circ} \mathrm{C}$
(d) $800{ }^{\circ} \mathrm{C}$

Fig. 10: Surface cracks of SCCPPF specimens using water cooling.

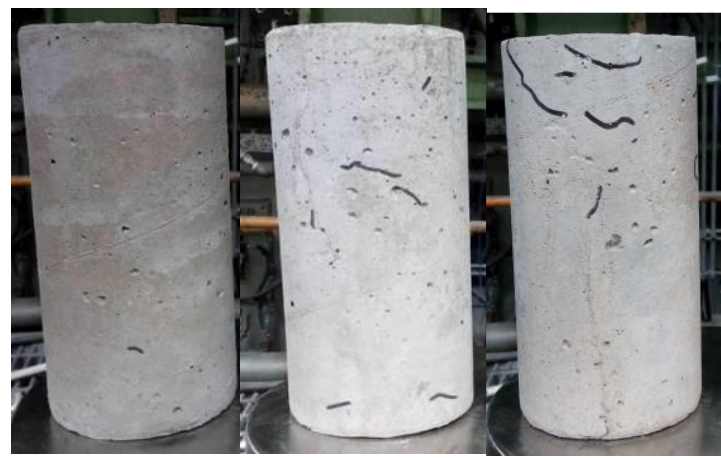

(a) $200{ }^{\circ} \mathrm{C}$

(b) $400{ }^{\circ} \mathrm{C}$

(c) $600{ }^{\circ} \mathrm{C}$

Fig. 11: Surface cracks of SCC specimens using air cooling.

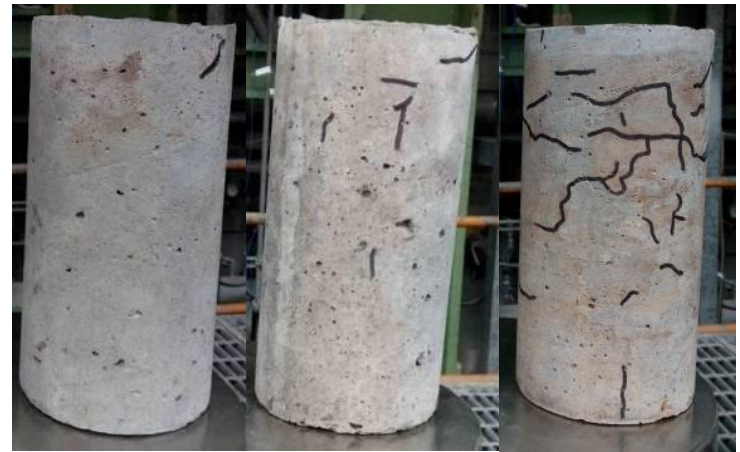
(a) $200{ }^{\circ} \mathrm{C}$
(b) $400{ }^{\circ} \mathrm{C}$
(c) $600{ }^{\circ} \mathrm{C}$

Fig. 12: Surface cracks of SCC specimens using water cooling.

\subsection{Residual Strengths of Concrete}

Table 2 shows the results of the residual compressive strengths of concrete specimens after fire. The ratio of the compressive strengths of concrete before and after fire is regarded as the residual compressive strength, expressed in percentage. .

From Table 2, it is seen that the residual compressive strengths of SCCPPF using air cooling for the temperatures of $200{ }^{\circ} \mathrm{C}, 400{ }^{\circ} \mathrm{C}, 600{ }^{\circ} \mathrm{C}$ and $800{ }^{\circ} \mathrm{C}$ are $96 \%, 82 \%, 58 \%$ and $28 \%$, respectively, and those of the residual compressive strengths of the SCCPPF specimens using water cooling are 93\%, 82\%, 49\% and 26\%, respectively. The result indicates that the decrease rates of residual strengths for the specimens using water cooling is larger than those of the specimens using air cooling. In addition, the residual compressive strengths of SCC using air cooling for the temperature of $200{ }^{\circ} \mathrm{C}$, $400{ }^{\circ} \mathrm{C}$ and $600{ }^{\circ} \mathrm{C}$ are $79 \%, 74 \%$ and $69 \%$, respectively, and those of the residual compressive strengths of the SCC specimens using water cooling are $67 \%, 63 \%$ and 51\%, respectively. The result shows a similar decrease tendency as that of SCCPPF, namely, the decreases rates of the residual strength of the specimens are larger for using water cooling. 
Figure 13 compares the decrease rate of the residual compressive strengths of SCCPPF and SCC. It is found that the residual compressive strength of SCCPPF at temperature of $200{ }^{\circ} \mathrm{C}$ is lower than that of SCC. The reason is that when the temperature exceeds $200{ }^{\circ} \mathrm{C}$, the PPFs will be melted to form pores in concrete. These pores may release the thermal deformation pressure, preventing the concrete from explosive failure, thus resulting in a larger residual strength of the SCCPPF. However, when the temperature raise to $400{ }^{\circ} \mathrm{C}$, the residual compressive strengths of SCCPPF decrease obviously; and the residual compressive strengths of SCCPPF and SCC specimens approach to each other gradually when the elevated temperature reaches $600{ }^{\circ} \mathrm{C}$. These results indicate that the PPF becomes invalid when the temperature exceeds $200{ }^{\circ} \mathrm{C}$, the residual compressive strengths of SCCPPF and SCC will not present any difference for the elevated temperature.

Table 2: The residual compressive strength after fire.

\begin{tabular}{|c|c|c|c|c|c|}
\hline concrete & $\begin{array}{c}\text { compressive strength } \\
(\mathrm{MPa})\end{array}$ & $\begin{array}{l}\text { comp } \\
\text { elevate }\end{array}$ & $\begin{array}{l}\text { sive str } \\
\text { tempera }\end{array}$ & $\begin{array}{l}\text { fter } \\
\mathrm{MPa})\end{array}$ & residual strength (\%) \\
\hline \multirow{8}{*}{ SCCPPF } & \multirow{8}{*}{42} & \multirow{4}{*}{$\begin{array}{l}\text { air } \\
\text { cooling } \\
\text { regime }\end{array}$} & $200^{\circ} \mathrm{C}$ & 40 & 96 \\
\hline & & & $400^{\circ} \mathrm{C}$ & 34 & 82 \\
\hline & & & $600^{\circ} \mathrm{C}$ & 22 & 52 \\
\hline & & & $800^{\circ} \mathrm{C}$ & 16 & 28 \\
\hline & & \multirow{4}{*}{$\begin{array}{l}\text { water } \\
\text { cooling } \\
\text { regime }\end{array}$} & $200^{\circ} \mathrm{C}$ & 39 & 93 \\
\hline & & & $400^{\circ} \mathrm{C}$ & 34 & 82 \\
\hline & & & $600^{\circ} \mathrm{C}$ & 20 & 49 \\
\hline & & & $800^{\circ} \mathrm{C}$ & 11 & 26 \\
\hline \multirow{8}{*}{$\mathrm{SCC}$} & \multirow{8}{*}{48} & \multirow{4}{*}{$\begin{array}{l}\text { air } \\
\text { cooling } \\
\text { regime }\end{array}$} & $200^{\circ} \mathrm{C}$ & 37 & 79 \\
\hline & & & $400^{\circ} \mathrm{C}$ & 35 & 74 \\
\hline & & & $600^{\circ} \mathrm{C}$ & 33 & 69 \\
\hline & & & $800^{\circ} \mathrm{C}$ & $*$ & $*$ \\
\hline & & \multirow{4}{*}{$\begin{array}{l}\text { water } \\
\text { cooling } \\
\text { regime }\end{array}$} & $200^{\circ} \mathrm{C}$ & 32 & 67 \\
\hline & & & $400^{\circ} \mathrm{C}$ & 30 & 63 \\
\hline & & & $600^{\circ} \mathrm{C}$ & 24 & 51 \\
\hline & & & $800^{\circ} \mathrm{C}$ & $*$ & * \\
\hline
\end{tabular}

* indicates no test data could be surveyed.

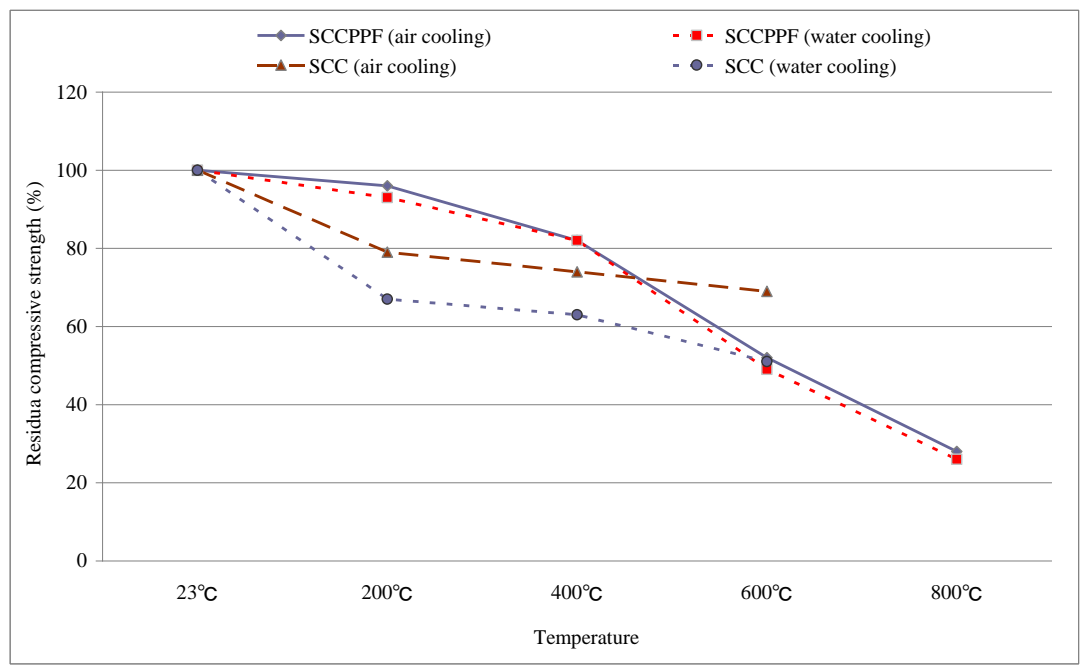

Fig. 13: Residual compressive strength of concrete vs. five temperatures. 


\section{Conclusion}

The experimental results indicate that the SCC specimens appeared explosive spelling at elevated temperature although they had been dried previously at the temperature of $105^{\circ} \mathrm{C}$ for 3,5 and 7 days. On the contrary, the specimens of SCCPP without drying previously haven't been presented any explosive spelling. The surface cracks of both concretes specimens increase with increasing temperature. The surface cracks of SCCPPF specimens using water cooling are wider and concentrated compared with those of SCC specimens. The residual compressive strengths of SCCPPF and SCC decrease with increasing temperature. Different cooling regimes affect the residual compressive strength of concrete. For the specimens tested at the temperatures of $200{ }^{\circ} \mathrm{C}$ and $400{ }^{\circ} \mathrm{C}$, the air cooling showed higher residual compressive strength than that of using water cooling. When the concrete specimens subjected to the elevated temperatures of $200{ }^{\circ} \mathrm{C}$ and $400{ }^{\circ} \mathrm{C}$, both cooling regimes exhibited similar residual compressive strength for the SCCPP specimens, however, the SCC presents lower residual compressive strengths with water cooling than that with air cooling.

\section{Acknowledgements}

The authors appreciate the Architecture and Building Research Institute (ABRI), Taiwan, for the financial support of this research. Gratefulness is also for the help of Dr. Chi-Chung Lee and Dr. Ming-ju Tsai of Fire Experiment Centre of ABRI during experiments.

\section{References}

[1] Q. Yua, Z. Taob, Y. X. Wu, "Experimental behaviour of high performance concrete filled steel tubular columns," Thin-Walled Structure, vol. 46, pp. 362-70, 2008.

[2] H. Fares, A. Noumowe and S. Remond, "Self-consolidating concrete subjected to high temperature: mechanical and physicochemical properties," Cement and Concrete Research, vol. 39, pp. 1230-1238, 2009.

[3] P. Kalifa, G. Chene and C. Galle, "High-temperature behavior of HPC with polypropylene fibers from spalling to microstructure," Cement Concrete Research, vol. 31, pp. 1487-1499, 2001.

[4] A. Behnood and M. Ghandehari, "Comparison of compressive and splitting tensile strength of high-strength concrete with and without polypropylene fibers heated to high temperatures," Fire Safety Journal, vol. 44, pp. 1015-1022, 2009.

[5] J. Xiao and H. Falkner, "On residual strength of high-performance concrete with and without polypropylene fibres at elevates temperatures," Fire Safety Journal, vol. 41, pp. 115-121, 2006.

[6] P. Pliya, A. L. Beaucour and A. Noumowe, "Contribution of cocktail of polypropylene and steel fibres in improving the behaviour of high strength concrete subjected to high temperature," Construction and Building Materials, vol. 25, pp. 1926-1934, 2011.

[7] A. Noumowe, "Mechanical properties and microstructure of high strength concrete containing polypropylene fibres exposed to temperatures up to $200^{\circ} \mathrm{C}$," Cement Concrete Research, vol. 35, pp. 2192-2198, 2005.

[8] S. L. Suhaendi and H. Takashi, "Effect of short fibers on residual permeability and mechanical properties of hybrid fibre reinforced high strength concrete after heat exposition," Cement Concrete Research, vol. 36, pp. 1672-1678, 2006.

[9] A. M. K. Abdelalim, G. E. Abdelaziz, M. A. K. Elmohr and G. A. Salama, "Effect of elevated fire temperature and cooling regime on the fire resistance of normal and self-compacting concrete," Engineering Research Journal, vol. 122, pp. 63-81, 2009. 